\title{
MicroRNA-34b promotes proliferation, migration and invasion of Ewing's sarcoma cells by downregulating Notch1
}

\author{
QUNSHAN LU ${ }^{1,2}$, MEI LU ${ }^{3}$, DONG $\mathrm{LI}^{4}$ and SHUAI ZHANG ${ }^{1}$ \\ ${ }^{1}$ Department of Orthopedics, Qilu Hospital of Shandong University, Jinan, Shandong 250012; ${ }^{2}$ Musculoskeletal Tumor Center, \\ Peking University People's Hospital, Beijing 100044; ${ }^{3}$ Department of Neurology, Qilu Hospital of Shandong University, \\ Jinan, Shandong 250012; ${ }^{4}$ Department of Orthopedics, Shandong Provincial Hospital \\ Affiliated to Shandong University, Jinan, Shandong 250012, P.R. China
}

Received November 15, 2017; Accepted April 23, 2018

DOI: $10.3892 / \mathrm{mmr} .2018 .9365$

\begin{abstract}
Ewing's sarcoma is the second most frequent bone and soft tissue sarcoma, which is commonly driven by the Ewing's sarcoma breakpoint region 1-friend leukemia integration 1 transcription factor (EWS-FLI1) fusion gene. Since microRNAs (miRs) can act as either oncogenes or tumor suppressor genes in human cancer, and miR-34b has been reported to act as a tumor suppressor, the role of miR-34b in Ewing's sarcoma was investigated in the present study. The results demonstrated that miR-34b expression levels were higher in tumor samples compared within normal tissue samples. Notably, miR-34b expression levels were significantly higher in EWS-FLI1-positive samples compared within EWS-FLI1-negative samples. The effects of miR-34b expression on cell proliferation, migration and invasion were also examined. miR-34b expression was inhibited using small interfering (si)RNA targeting the fusion gene. Transfection of a miR-34b precursor sequence into siRNA-treated tumor cells resulted in a significant increase in cell growth, migration and invasion compared within the control group. In addition, the adhesive ability was increased in the Ewing's sarcoma cell line RD-ES, but not A673, following miR-34b upregulation. Conversely, downregulation of miR-34b expression led to a significant decrease in cell growth, migration and invasion. Notch has previously been reported to serve either oncogenic or tumor suppressive roles in human cancer. The results indicated that Notch1 and its target genes, Hes family BHLH transcription factor 1 and Hes-related family BHLH transcription factor with YRPW motif 1, were suppressed by miR-34b directly In conclusion, EWS-FLI1 may modulate miR-34b expression directly or indirectly, and miR-34b potentially has an oncogenic role in Ewing's sarcoma by downregulating Notch1.
\end{abstract}

Correspondence to: Dr Shuai Zhang, Department of Orthopedics, Qilu Hospital of Shandong University, 107 Wenhuaxi Road, Jinan, Shandong 250012, P.R. China

E-mail: zhangshuai1106@126.com

Key words: miR-34b, Ewing's sarcoma, oncogene, Notch1

\section{Introduction}

Ewing's sarcoma belongs to the Ewing's sarcoma family of tumors (ESFT). It is the second most frequent bone and soft tissue sarcoma, affecting mostly adolescents and young adults. Ewing's sarcoma is characterized by unique chromosomal translocations involving fusion of the 5'segment of the Ewing's sarcoma breakpoint region 1 (EWS) gene to the 3 'segment of an E26 transformation-specific (ETS) family gene, with the most common fusion taking place with friend leukemia integration 1 transcription factor (FLI1) (1). Although the 5-year survival rate of Ewing's sarcoma has been improved through multimodal therapy, patients with metastasis at diagnosis still have poor clinical outcomes (2-4). It has been hypothesized that the EWS-FLI1 fusion protein is involved in a key oncogenic event in ESFT by inducing and repressing specific target genes (5-7), thereby promoting tumor growth. Although previous studies have identified the factors that modulate or are modulated by EWS-FLI1 (8-10), the mechanisms underlying the development of Ewing's sarcoma are not yet fully understood.

Several studies have suggested that the EWS-FLI1 fusion gene is implicated in Ewing's sarcoma by modulating microRNA (miRNA/miR) expression (11-13). miRNAs are a class of small noncoding RNAs that regulate gene expression by targeting mRNA $(14,15)$. Although the biological functions of miRNAs remain largely unknown, there is some evidence that miRNAs can act as oncogenes or tumor suppressor genes to regulate cell proliferation, differentiation, apoptosis and metastasis by altering expression of their target genes $(16,17)$. Since miRNAs can be regulated by EWS-FLI1, they may represent potential downstream targets in Ewing's sarcoma $(11-13,18,19)$.

The miR-34 family is a collection of evolutionarily conserved miRNAs, which has been associated with tumor suppression and is downregulated in human tumors (20-22). miR-34a, a member of miR-34 family, has been reported to predict the survival of patients with Ewing's sarcoma, and directly affects the chemosensitivity of tumor cells and malignancy (23). However, miR-34b has not been specifically detected in Ewing's sarcoma. The aim of the present study was to investigate the effects of miR-34b, as well as those of its direct target gene, Notch1, in promoting Ewing's sarcoma growth and metastasis $(24,25)$. 


\section{Materials and methods}

Patients and cell culture. Tumor and normal tissue biopsy samples were collected respectively from 14 patients with Ewing's sarcoma from 2010 to 2016 at the Qilu Hospital of Shandong University (Jinan, China) and the Shandong Provincial Hospital Affiliated to Shandong University (Jinan, China), including 5 females and 9 males whose age from 12 to 23 years old. Patients did not receive therapy at the time of sample collection. The present study was approved by the Institutional Review Boards of Qilu Hospital of Shandong University and Shandong Provincial Hospital Affiliated to Shandong University. Written informed consent was provided by all patients for the experimental use of surgical specimens.

Cell lines were obtained from American Type Culture Collection (ATCC; Manassas, VA, USA). The NIH 3T3 cell line and the human Ewing's sarcoma cell line A673 was cultured in Dulbecco's modified Eagle's medium (DMEM; HyClone; GE Healthcare, Logan, UT, USA) supplemented with $10 \%$ fetal bovine serum (FBS; Gibco; Thermo Fisher Scientific, Inc., Waltham, MA, USA), and RD-ES cells were cultured in RPMI-1640 medium (HyClone; GE Healthcare) supplemented with 15\% FBS (Gibco; Thermo Fisher Scientific, Inc.). The cell lines were maintained at $37^{\circ} \mathrm{C}$ in a humidified chamber containing $5 \% \mathrm{CO}_{2}$.

Transfection. RD-ES and A-673 Cells (1x10 $/ \mathrm{L})$ were transfected with $20 \mathrm{nM}$ small interfering RNA (siRNA) (Shanghai GeneChem Co., Ltd., Shanghai, China) targeting EWS-FLI-1 using Lipofectamine ${ }^{\circledR} 2000$ reagent (Invitrogen; Thermo Fisher Scientific, Inc.) according to the manufacturer's protocol. The RNA sequences used are as follows: EWS-FLI-1-specific siRNA, sense 5'-GUACCCUUCUGACAUCUCCUTT-3', antisense 5'-AGGAGUGUCAGAAGGGUACTT-3'; and non-silencing control siRNA, sense 5'-UUCUCCGAACGU GUCACGUTT-3' and antisense 5'-ACGUGACACGUUCGG AGAATT-3'. Infected cells were incubated for $24 \mathrm{~h}$ at $37^{\circ} \mathrm{C}$ and used for further experiments.

The precursor (miRBase accession no. MI0000742) or complementary miR-34b sequence (miRBase accession no. MIMAT0000685) was inserted into a lentiviral vector (Shanghai Genechem Co., Ltd., Shanghai, China; cat. nos. PMUL217000742 and PMDL159000685, respectively) to up- or downregulate miR-34b expression as previously described (26). [Anti-miRNA oligonucleotides (AMOs): Ammunition to target miRNAs implicated in human disease]. The cells were infected with the lentiviral vectors $\left(1 \times 10^{8} \mathrm{TU} / \mathrm{ml}\right)$ according to manufacturer's protocol.

Reverse transcription-polymerase chain reaction (RT-PCR) and RT-quantitative PCR. Total RNA was extracted from cell lines and tumor and normal tissue biopsy samples using TRIzol $^{\circledR}$ reagent (Invitrogen; Thermo Fisher Scientific, Inc.) according to the manufacturer's protocol, and the RNA was subsequently reverse-transcribed into complementary DNA using SuperScript ${ }^{\mathrm{TM}}$ First-Strand Synthesis System (Invitrogen; Thermo Fisher Scientific, Inc.; cat. no. 11904-018; Table I). For reverse transcription reactions, 10 ng total RNA was used in each reaction $(5 \mu \mathrm{l})$ and mixed with the RT primer ( $3 \mu \mathrm{l})$. The RT reaction was carried out at $16^{\circ} \mathrm{C}$ for $30 \mathrm{~min}$;
Table I. Stem-loop reverse transcription primers for miR-34b and U6.

\begin{tabular}{ll}
\hline Name & \multicolumn{1}{c}{ Reverse transcription primer (5'-3') } \\
\hline hsa-miR-34b & GTCGTATCCAGTGCAGGGTCCGAGGTA \\
TTCGCACTGGATACGAC ATGGCAGT \\
U6 & AAAAATATGGAACGCTT
\end{tabular}

miR, microRNA; U6, U6 small nuclear RNA.

$42^{\circ} \mathrm{C}$ for $30 \mathrm{~min} ; 85^{\circ} \mathrm{C}$ for $5 \mathrm{~min}$; and then maintained at $4^{\circ} \mathrm{C}$. The specific primers used for EWS-FLI1, EWS-ERG and miR amplification are summarized in Table II. The amplified PCR products were separated by $1.5 \%$ agarose gel electrophoresis and visualized in gel with ethidium bromide under ultraviolet light. RT-qPCR was performed using an ABI Prism7300 Sequence Detection system (Applied Biosystems; Thermo Fisher Scientific, Inc.) using the GoTaq qPCR Master Mix A6001 kit (Promega Corporation, Madison, WI, USA). The following thermocycling conditions were used: Denaturation at $95^{\circ} \mathrm{C}$ for $15 \mathrm{~min}$, followed by 40 cycles of amplification at $95^{\circ} \mathrm{C}$ for $15 \mathrm{sec}$ and $58^{\circ} \mathrm{C}$ for $30 \mathrm{sec}$ for extension, followed by maintenance at $4^{\circ} \mathrm{C}$. GAPDH and U6 was used as an endogenous control and reference gene for relative quantifications of the $2^{-\Delta \Delta C q}$ analysis method (27). Experiments were performed in triplicate.

Western blot analysis. Western blot analysis was performed as previously described (13). Briefly, Ewing's sarcoma cells and 3 T3 cells were washed twice with ice-cold PBS and lysed in radioimmunoprecipitation assay lysis buffer $(20 \mathrm{mmol} / \mathrm{l}$ of Tris-HCl, $150 \mathrm{mmol} / \mathrm{l}$ of $\mathrm{NaCl}, 1 \% \mathrm{NP}-40,5 \mathrm{mmol} / \mathrm{l}$ of EDTA, and $1 \mathrm{mmol} / \mathrm{l}$ of $\mathrm{Na}_{3} \mathrm{VO}_{4}, \mathrm{pH} 7.5$ ) containing protease inhibitor cocktail (Sigma-Aldrich; Merck KGaA) and then incubated for $25 \mathrm{~min}$ at $4^{\circ} \mathrm{C}$ and centrifuged for $20 \mathrm{~min}$ at $13,000 \mathrm{x} \mathrm{g}$ at $4^{\circ} \mathrm{C}$. Thereafter, the supernatant was recovered and quantified using the Pierce bicinchoninic acid protein quantification assay (Pierce; Thermo Fisher Scientific, Inc.). An aliquot (50-100 mg of protein per lane) of the total protein was loaded onto $10 \%$ SDS-PAGE and then blotted to polyvinylidene fluoride membranes (Bio-Rad Laboratories, Inc., Hercules, CA, USA). Individual immunoblots were performed with primary antibodies against Notch1 (1:1,000; cat. no. ab8925; Abcam, Cambridge, MA, USA), Hes family BHLH transcription factor 1 (1:1,000; Hes1; cat. no. ab71559; Abcam), Hes-related family BHLH transcription factor with YRPW motif 1 (1:1,000; Hey1; cat. no. ab22614; Abcam) and $\beta$-actin $(1: 2,000$; cat no. sc-130065; Santa Cruz Biotechnology, Inc., Dallas, TX, USA). Briefly, membranes were blocked in Tris-buffered saline with 20\% Tween (TBST) buffer containing 5\% nonfat dry milk for $2 \mathrm{~h}$ at room temperature and incubated overnight with primary antibody. Subsequently, membranes were incubated with horseradish peroxidase-conjugated secondary antibodies (Santa Cruz Biotechnology, Inc.) for $1 \mathrm{~h}$. Enhanced chemiluminescent reagent (GE Healthcare, Chicago, IL, USA) was used for protein visualization. Experiments were performed in triplicate. 
Table II. Specific primers for reverse transcription-quantitative polymerase chain reaction.

\begin{tabular}{lll} 
Name & \multicolumn{1}{c}{ Forward primer $\left(5^{\prime}-3^{\prime}\right)$} & \multicolumn{1}{c}{ Reverse primer (5'-3') } \\
\hline $\begin{array}{l}\text { hsa-miR-34b } \\
\text { U6 }\end{array}$ & TGCGGTCAATCACTAACTCC & CGTGCAGGGTCCGAGGT \\
GAPDH & CTCGCTTCGGCAGCACA & AACGCTTCACGAATTTGCGT \\
EWS-FLI1 & CCCAAGCTTATGGCGTCCACGGATTAC & TGGTGAAGACGCCAGTGGA \\
EWS-ERG & CGACTAGTTATGATCAGAGCAGT & AGCAGCTCCAGGAGGAATTGCCA \\
Notch-1 & TCAGCGGGATCCACTGTGAG & ACACAGGCAGGTGAACGAGTTG \\
Notch-2 & CAACCGCAATGGAGGCTATG & GCGAAGGCACAATCATCAATGTT \\
Notch-3 & TGGCGACCTCACTTACGACT & CACTGGCAGTTATAGGTGTTGAC \\
Notch-4 & CCTGGCTCCTTCAACTGCC & GCAAGTAGGTCCAGACAGGT \\
Hes-1 & GAGCACAGAAAGTCATCAAAGC & ATTTCCAGAATGTCCGCCTTC \\
Hey-1 & TTCAAGGCAGCTCGGTAACT & GGGCATTTTACTTCCCCAAT
\end{tabular}

EWS, Ewing's sarcoma breakpoint region 1; FLI1, friend leukemia integration 1 transcription factor; Hes1, Hes family BHLH transcription factor 1; Hey1, Hes-related family BHLH transcription factor with YRPW motif 1; miR, microRNA; U6, U6 small nuclear RNA.

Cell proliferation and adhesion assays. Cell proliferation was determined by the MTT assay. Following infection by EWS-FLI-1 siRNA and miR-34b precursor or inhibitor, Cells were trypsinized and $5 \times 10^{3}$ cells/well were seeded into 96 -well plates in triplicate. Cellular proliferation was determined once a day over the course of 5 days. Briefly, $20 \mu 15 \mathrm{mg} / \mathrm{ml}$ MTT was added to each well and cells were incubated at $37^{\circ} \mathrm{C}$ in a humidified atmosphere containing $5 \% \mathrm{CO}_{2}$. Cells were lysed after 4-6 h using cell lysis reagent (20\% sodium dodecyl sulfate, $50 \%$ dimethyl sulfoxide, $\mathrm{pH} 4.7$ ), and absorbance was measured at $570 \mathrm{~nm}$ with an EL-311SX microplate reader (BioTek Instruments, Inc., Winooski, VT, USA).

The adhesion assay was performed using MTT-stained cells. At $24 \mathrm{~h}$ following infection by siRNA targeting EWS/FLI1 and miR-34b precursor or inhibitor at $37^{\circ} \mathrm{C}$, the Ewing sarcoma cells $\left(1 \times 10^{5}\right)$ were resuspended in $200 \mathrm{ml}$ medium without serum and seeded into a Matrigel-precoated (100 mg/ml) 96-well plate. Cells were washed after 30 and $60 \mathrm{~min}$ to remove non-adherent cells. After the final wash, absorbance was measured at $490 \mathrm{~nm}$ to quantify adherence. Experiments were repeated three times.

Cell migration and invasion assays. Migration assays for A673 or RD-ES cells were performed by seeding $3 \times 10^{5}$ cells in $200 \mu \mathrm{l}$ DMEM or RPMI serum-free medium in the upper chambers of 24-well Transwell inserts with polyethylene terephthalate membranes $(8.0-\mu \mathrm{m}$ pore size; Costar, Corning Inc., Corning, NY, USA). The lower chambers were filled with $0.8 \mathrm{ml}$ DMEM or RPMI supplemented with $15 \%$ FBS. After $24 \mathrm{~h}$ incubation at $37^{\circ} \mathrm{C}$, the non-migrating cells were removed; and the membranes were fixed and stained using the Differential Quik Stain kit (Sysmex Corporation, Kobe, Japan). Cells that migrated through the membranes were quantified using NIKON LABOPHOT optical light microscopic visualization (magnification $\mathrm{x} 200$ ) and by randomly selecting 10 regions for cell counting. Experiments were performed in triplicate.

The procedure for the invasion assay was similar to the migration assay. Briefly, the membranes in the Transwell inserts were coated evenly with $25 \mu \mathrm{l}$ Matrigel $(100 \mathrm{mg} / \mathrm{ml})$ per well (BD Biosciences, Franklin Lakes, NJ, USA; cat. no. 356234) before cells were seeded into the upper chamber. After incubation for 36 and $48 \mathrm{~h}$ for A673 and RD-ES cells, respectively, invaded cells on the lower surface of the membrane were analyzed as previously described in the migration assay.

Luciferase reporter assay. The 3'-untranslated region (UTR) of Notch1 was amplified from human genomic DNA and cloned into the pmiR-RB-REPORT ${ }^{\mathrm{TM}}$ reporter gene plasmid vector (Guangzhou RiboBio Co., Ltd., Guangzhou, China) with restriction enzymes XhoI and NotI. Similarly, a fragment representing mutant Notch1 3'-UTR, harbouring the change of the seven miRNA34b-binding sites (ACUGCCU $\rightarrow$ UGA CGGA), was cloned into the pmiR-RB-REPORT vector as a control. For reporter assays, $1 \times 10^{5} / 1$ cells were plated in a 24-well culture plate at a density of 8,000 cells/well and co-transfected with the reporter plasmid and $100 \mathrm{nM}$ miR-34b inhibitor or miR inhibitor negative control (NC) (NC sequence: 5'-UUGUACUACACAAAAGUACUG-3') which were synthesized by Shanghai GenePharma Co., Ltd., with Lipofectamine 2000 (Invitrogen; Thermo Fisher Scientific, Inc.) according to the manufacturer's protocol Luciferase activity was measured $48 \mathrm{~h}$ post-transfection using the Dual-Luciferase ${ }^{\circledR}$ Reporter Assay system (Promega Corporation, Madison, WI, USA), according to the manufacturer's protocol. Firefly luciferase activity was normalized against Renilla luciferase activity for each transfected well to normalize transfection efficiency.

Statistical analysis. The results of RT-qPCR, proliferation, adhesion, migration and invasion assays are presented as the means \pm standard error. Each assay was performed in triplicate Data were analyzed by one-way analysis of variance. All statistical analyses were performed using the SPSS 13.0 statistical software package (SPSS, Inc., Chicago, IL, USA). $\mathrm{P}<0.05$ was considered to indicate a statistically significant difference. 


\section{Results}

Expression levels of EWS-FLII and miR-34b in biopsy samples. A large proportion (85-90\%) of Ewing's sarcoma cases are characterized by the EWS-FLI1 fusion gene (28). Therefore, the expression levels of the fusion gene were detected in Ewing's sarcoma and normal tissue (NT) biopsy samples using RT-PCR. The results demonstrated that NT did not express the EWS-FLI1 fusion gene (Fig. 1A) and 3/14 tumor samples did express EWS-ERG fusion gene (Fig. 1B). The results of 10 samples and 1 NT are presented in the Fig. 1A because the lanes of gel electrophoresis were limited in our laboratory.

The expression levels of miR-34b in tumor samples and NT were measured using stem-loop RT-qPCR. The results demonstrated that tumor samples expressed increased levels of miR-34b compared with NT. Notably, miR-34b was expressed at higher levels in EWS-FLI1-positive samples compared within EWS-ERG-positive samples (Fig. 1C). These results indicated that the EWS-FLI1 gene may have greater controlover miR-34 be xpression than the EWS-ERG gene.

EWS-FLI1 fusion gene may affect miR-34b expression in Ewing's sarcoma cell lines. RD-ES and A673 cells are known to possess the EWS-FLI1 fusion gene (29). Ewing sarcoma cells secrete EWS/Fli-1 fusion mRNA via microvesicles. NIH3T3 cells were detected as negative control. Therefore, EWS-FLI1 expression levels in these cell lines were detected using RT-PCR (Fig. 2A). The expression of the fusion gene was successfully downregulated by siRNA in RD-ES cells and A673 cells (Fig. 2B). In addition, the relative miR-34b expression levels were detected in cell lines with or without the interrupted fusion gene. As presented in the figure, miR-34b expression in RD-ES and A673 cells was downregulated following siRNA transfection (Fig. 2C and D). These results indicated that the EWS-FLI1 fusion gene may be associated with miR-34b expression in Ewing's sarcoma cell lines, which is consistent with the observations made in the tumor biopsy samples.

Up- and downregulation of $m i R-34 b$ expression. $\mathrm{miR}-34 \mathrm{~b}$ expression can be controlled by the EWS-FLI1 fusion gene; in addition, in the present study its expression was altered using lentiviral vectors. The lentiviral vector with complementary sequences of miR-34b was infected into normal cells to downregulate miR-34b expression, whereas the lentiviral vector with precursor sequences of miR-34b was infected into siRNA-transfected cells to upregulate miR-34b expression. As shown in Fig. 2E and F, miR-34b expression was successfully up- and downregulated by precursor and complementary miR-34b sequences, respectively.

miR-34b promotes proliferation of Ewing's sarcoma cells in vitro. To investigate the effects of $\mathrm{miR}-34 \mathrm{~b}$ on proliferation of Ewing's sarcoma cell lines, an MTT assay was performed. The results demonstrated that when miR-34b expression was upregulated, the siRNA-transfected RD-ES and A673 cells in which EWS-FLI1 was downregulated exhibited a significant increase in proliferative capacity compared with the cells in the control groups (Fig. 3A and B). Conversely, the proliferative

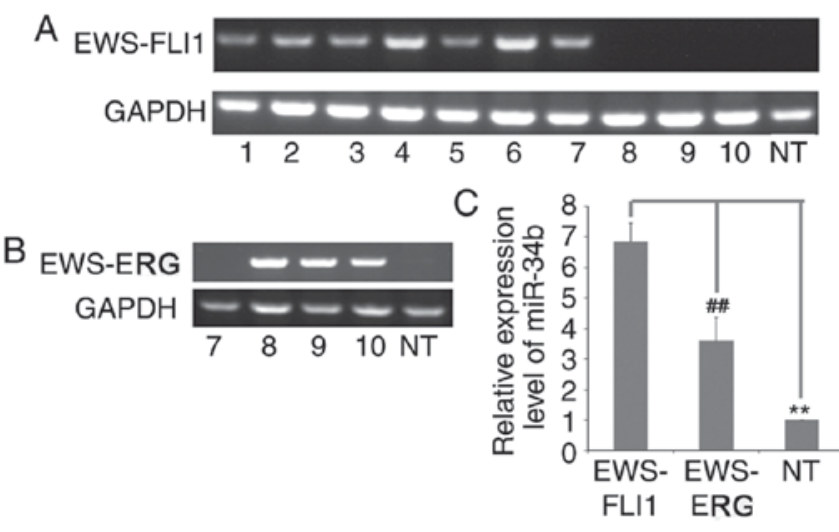

Figure 1. Association between the EWS-FLI1 fusion gene and miR-34b in tumor and NT samples. (A) EWS-FLI1 was not detected in three tumor samples and in NT. (incomplete data presented due to limited lanes). (B) EWS-ERG was detected in three tumor samples. Lanes 1-7, EWS-FLI1-positive samples; lanes 8-10, EWS-ERG-positive samples. (C) Expression levels of miR-34b were increased in tumor samples compared with in NT. In EWS-FLI1-positive samples, miR-34b relative expression was higher compared with in NT. ${ }^{* *} \mathrm{P}<0.01$ vs. NT, ${ }^{\# \#} \mathrm{P}<0.01$ vs. EWS-ERG positive samples. EWS, Ewing's sarcoma breakpoint region 1; FLI1, friend leukemia integration 1 transcription factor; miR, microRNA; NT, normal tissue.

ability of normal RD-ES and A673 cells was significantly inhibited when miR-34b expression was downregulated (Fig. 3C and D). These results indicated that miR-34b may promote cell proliferation in Ewing's sarcoma.

miR-34b promotes RD-ES, but not A673, cell adhesion in vitro. The adhesion of cancer cells to the extracellular matrix has a significant role in metastasis after disaggregation from the primary tumor. Therefore, an inhibition of adhesion may contribute to a reduction in metastatic potential. The present study demonstrated that upregulation of miR-34b expression significantly increased the adhesion of RD-ES cells, whereas up- or downregulation of miR-34b had little effect on A673 cell adhesion (Fig. 3E and F).

miR-34b improves the migration and invasion of Ewing's sarcoma cells in vitro. Migration and invasion of tumor cells are indispensable for metastasis in vivo; therefore, inhibiting the migratory and invasive capacity of Ewing's sarcoma cells may decrease metastatic potential. In the present study, the effects of miR-34b on the migratory and invasive properties of Ewing's sarcoma cell lines were investigated using Transwell assays. As shown in Fig. 4, the ability of RD-ES cells to migrate and invade was significantly inhibited when miR-34b expression was downregulated. Similar results were also obtained using A673 cells (data not shown).

Effects of miR-34b on Notch1, Hesl and Heyl in Ewing's sarcoma cells. To determine the molecular mechanisms involved in miR-34b-induced cell proliferation and migration, the Notch signaling pathway was investigated as it is a target of miR-34b and exhibits the opposite role in suppressing tumor development. When miR-34b expression was inhibited, the RT-qPCR results demonstrated that Notch1 expression was increased compared with the other three Notch receptors 
A
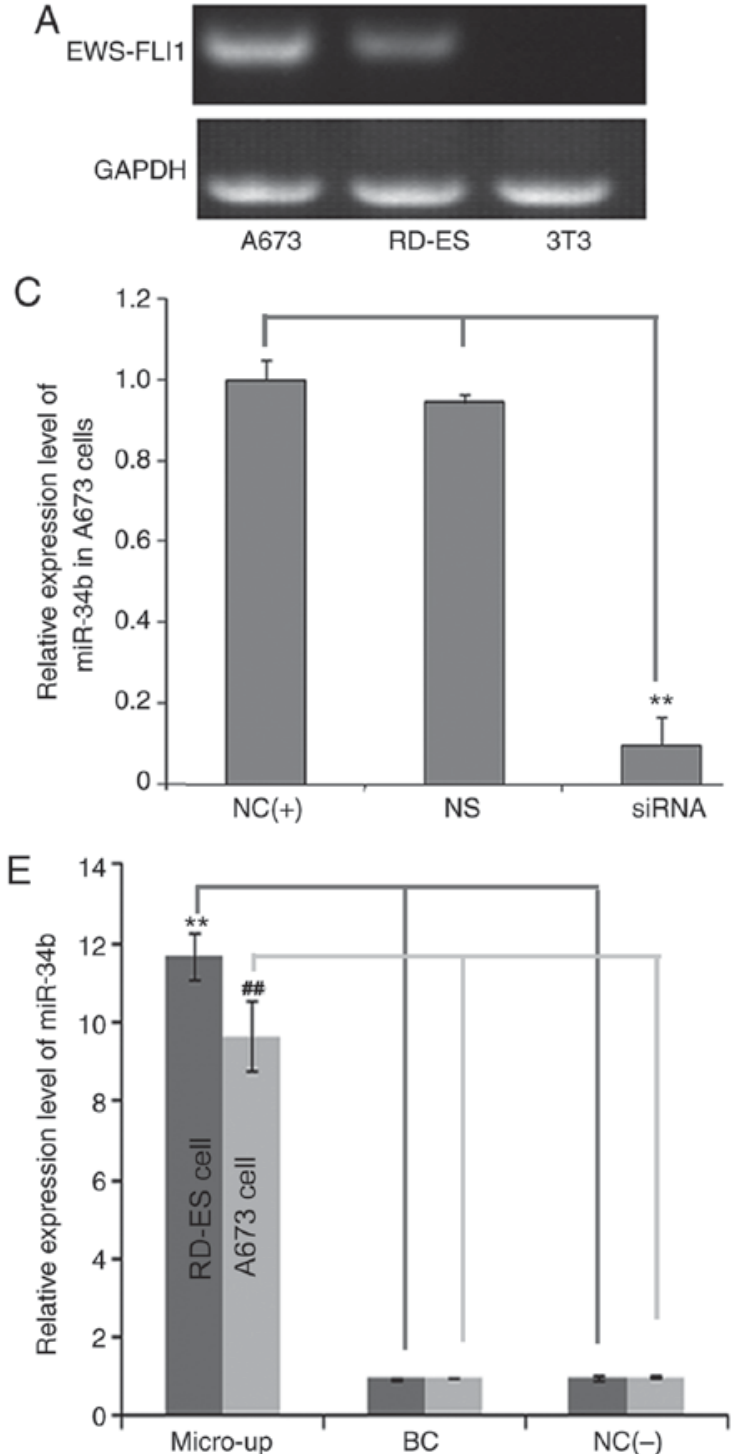

B
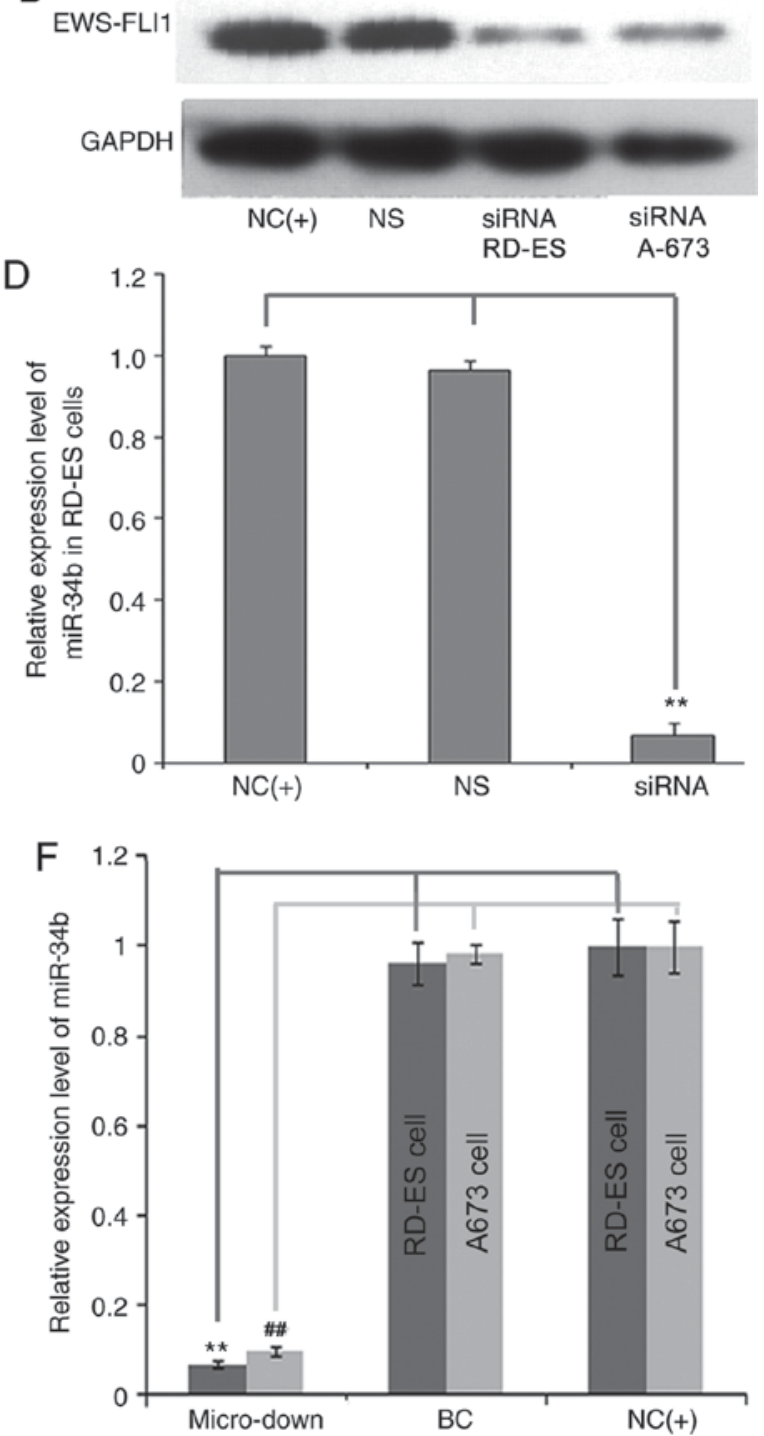

Figure 2. (A) Detection of EWS-FLI1 fusion gene expression in RD-ES and A673 cell lines using reverse transcription-polymerase chain reaction. (B) Expression levels of the fusion gene were downregulated in RD-ES and A-673 cells following siRNA transfection. (C) miR-34b expression in A673 cells was downregulated following siRNA transfection. (D) miR-34b expression in RD-ES cells was downregulated following siRNA transfection. (E) miR-34b expression was upregulated by the precursor of miR-34b in RD-ES and A-673 cells. (F) miR-34b expression was downregulated by the inhibitor of miR-34b in RD-ES and A-673 cells. BC, cell lines that were treated with lentiviral vector alone; $\mathrm{NC}(+)$, normal cell lines that were not transfected with siRNA; NS, cells transfected with non-targeting siRNA; siRNA, siRNA-transfected cells; NC(-), normal cell lines that were transfected with specific siRNA targeting the EWS-FLI1 fusion gene; Micro-up, NC(-) cell lines treated with precursor miR-34b sequences; Micro-down, $\mathrm{NC}(+)$ cell lines treated with complementary sequences of miR-34b. ${ }^{* *} \mathrm{P}<0.01,{ }^{\# \#} \mathrm{P}<0.01$. EWS, Ewing's sarcoma breakpoint region 1; FLI1, friend leukemia integration 1 transcription factor; miR, microRNA; siRNA, small interfering RNA.

(data not shown). Therefore, the expression levels of Notch1, and its target genes, Hes1 and Heyl, in RD-ES and A673 cells were further assessed by RT-qPCR analysis. Compared with in normal cells, the expression levels of Notch1, Hesland Heyl were increased when the EWS-FLI1 fusion gene was silenced by siRNA in RD-ES and A673 cells (Fig. 5A). Conversely, the expression levels of Notch1, Hes1 and Heyl were decreased after the cells in which EWS/FLI1 expression was downregulated with the siRNA were transfected with miR-34b precursor sequences (Fig. 5B). Furthermore, there was an increase in the expression levels of Notch1, Hes1 and Heyl after miR-34b downregulation (Fig. 5C).

The protein expression levels of Notch1, Hes1 and Hey1 were examined by western blot analysis. In agreement with the RT-qPCR data, it was also demonstrated that miR-34b was able to downregulate Notch1, Hes1 and Hey1 protein expression (Fig. 6). These results suggested that the EWS-FLI1 fusion gene mayinactivate the Notch1 signaling pathway in Ewing's sarcoma via miR-34b.

miR-34b directly modulates expression of the Notch1 gene in Ewing's sarcoma cells in vitro. A dual-luciferase reporter assay was conducted to confirm the effects of miR-34b on Notch1. Fragments containing the miR-34b binding sequence or mutated sequence in the 3'-UTR of the Notch1 mRNA were cloned into the pmiR-RB-REPORT luciferase reporter vector to generate the pmiR-RB-REPORT-NOTCH1-3'UTR and pmiR-RB-REPORT-NOTCH1-3'UTR-MUT plasmids, 
A
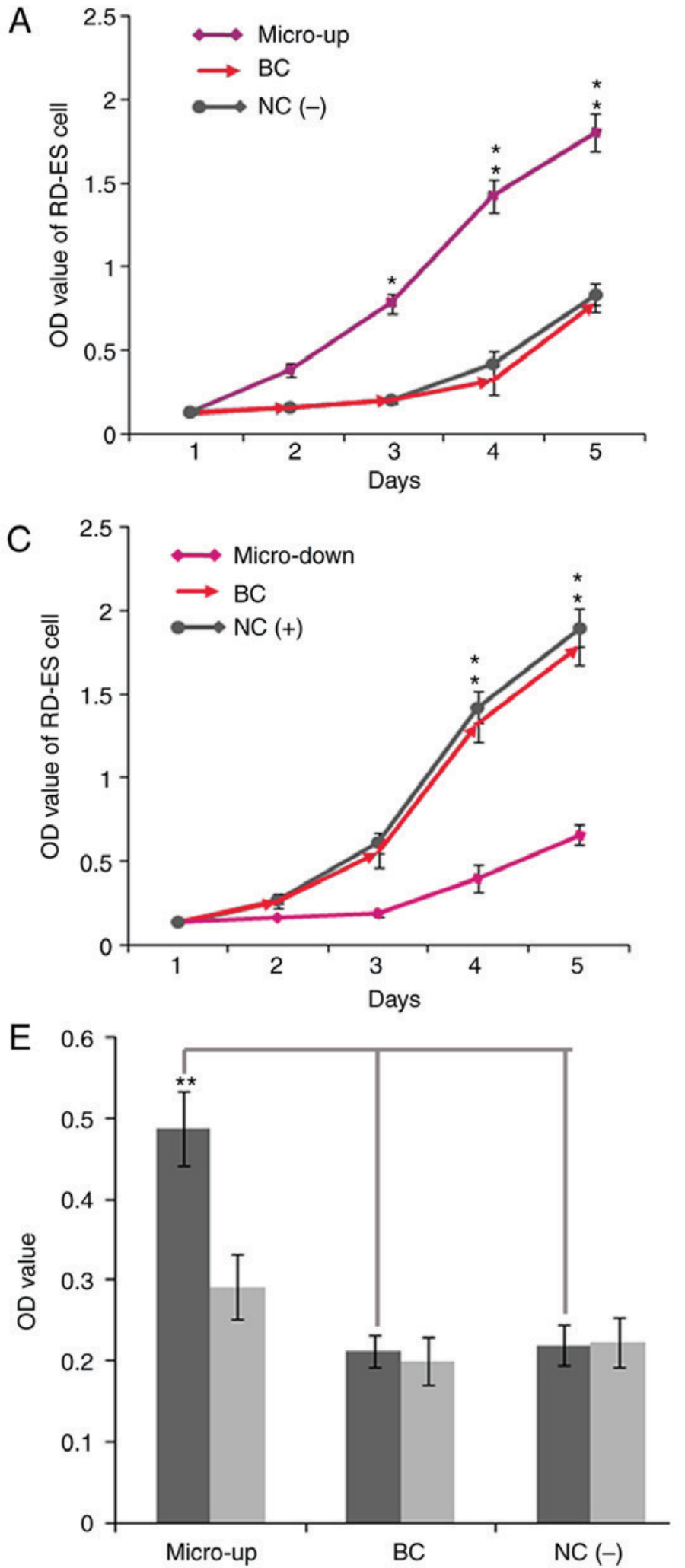
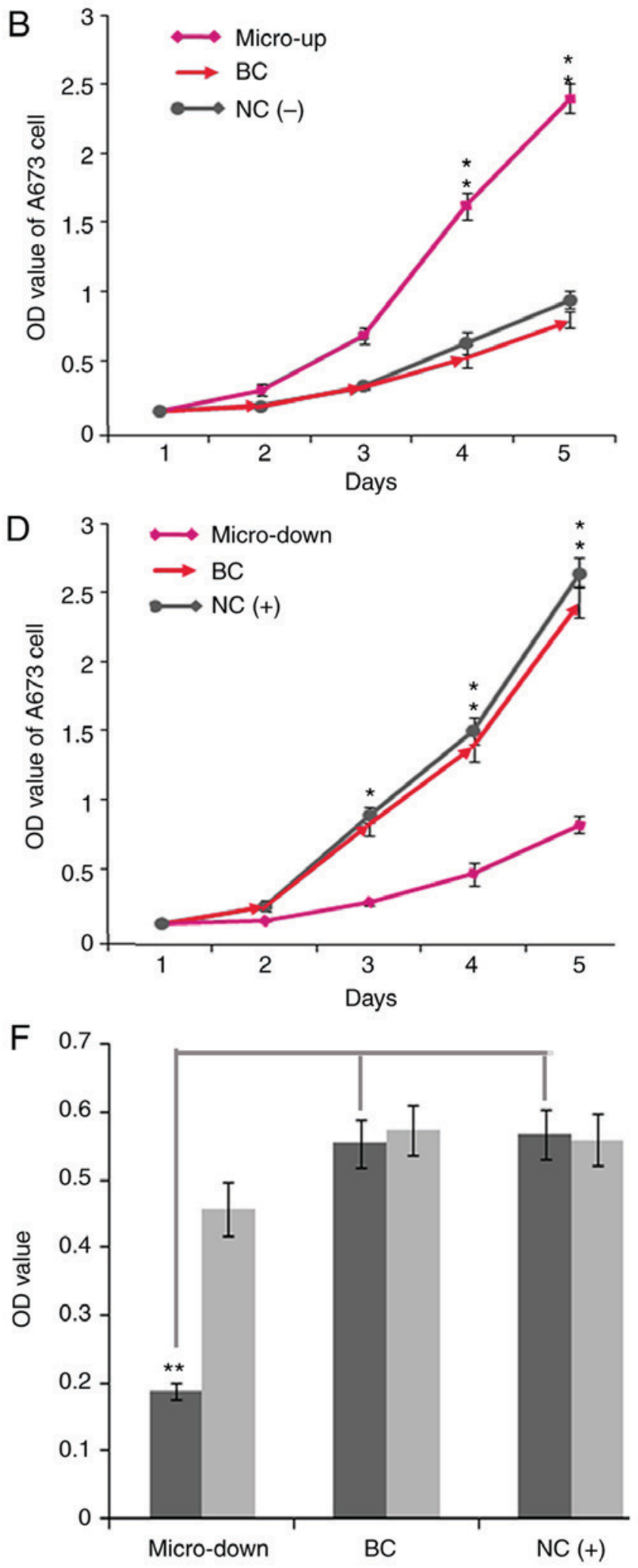

RD-ES

A673

Figure 3. Proliferation and adhesion of RD-ES and A673 cells were detected using an MTT assay. (A) When miR-34b expression was upregulated, the siRNA-transfected RD-ES cells exhibited significantly increased proliferative capacity compared with cells in the control groups. (B) When miR-34b expression was upregulated, the siRNA-transfected A673 cells exhibited significantly increased proliferative capacity. (C) Proliferative ability of normal RD-ES cells was significantly inhibited when miR-34b expression was downregulated. (D) Proliferative of normal A673 cells was significantly inhibited when miR-34b expression was downregulated. (E) Overexpression of miR-34b significantly improved the adhesion of RD-ES cells, but had little effect on A673 cells. (F) Knockdown of miR-34b reduced the adhesive ability of RD-ES cells, but had little effect on A673 cells. BC, cell lines that were treated with lentiviral vector alone; $\mathrm{NC}(+)$, normal cell lines that were not transfected with siRNA; siRNA, siRNA-transfected cells; NC(-), normal cell lines that were transfected with specific siRNA; Micro-up, cell lines treated with precursor miR-34b sequences; Micro-down, cell lines treated with complementary sequences of miR-34b. ${ }^{~} \mathrm{P}<0.05$ and ${ }^{* *} \mathrm{P}<0.01$. miR, microRNA; OD, optical density; siRNA, small interfering RNA. 
A Migration

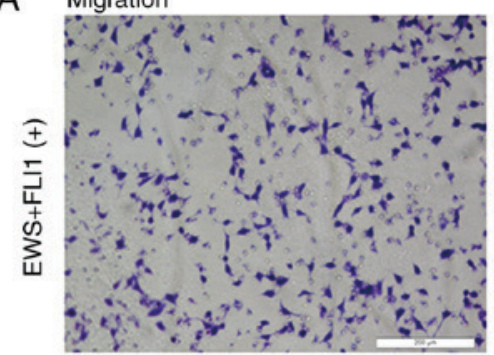

Micro-down

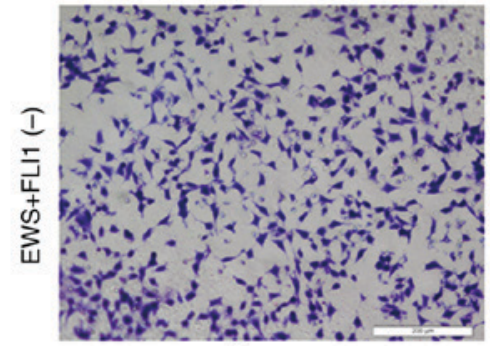

Micro-up

B

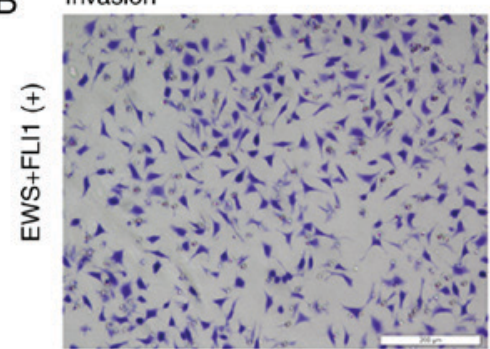

Micro-down

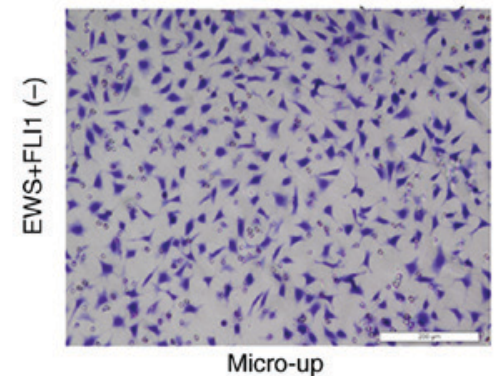

Micro-up

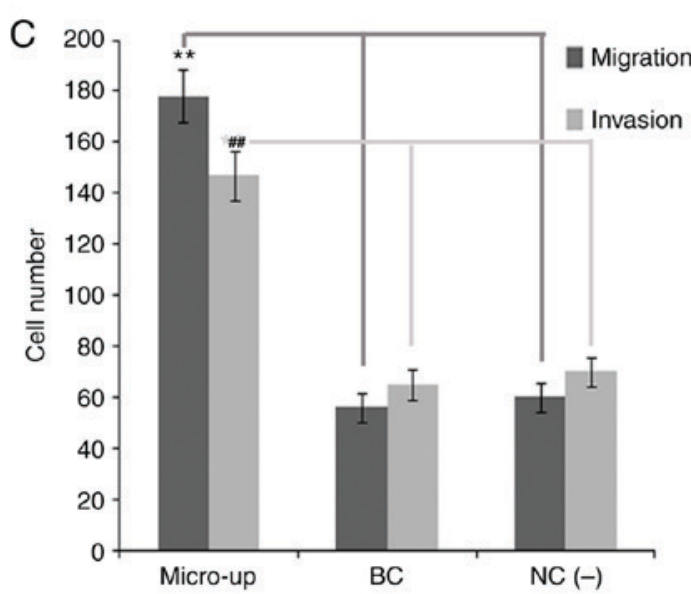

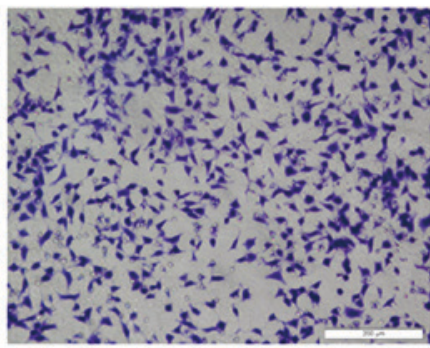

BC

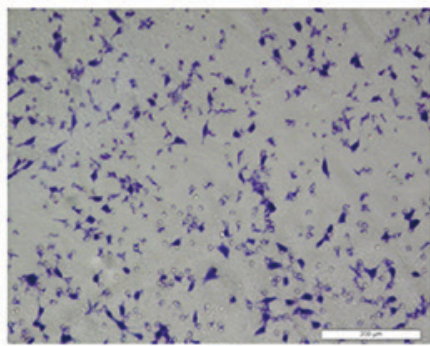

$\mathrm{BC}$

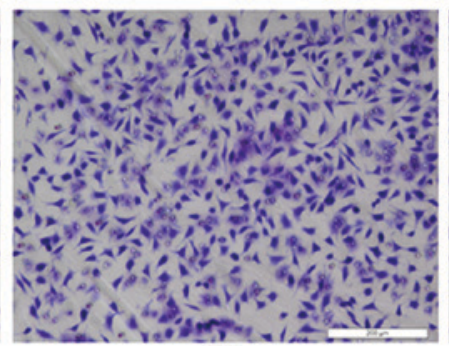

$\mathrm{BC}$

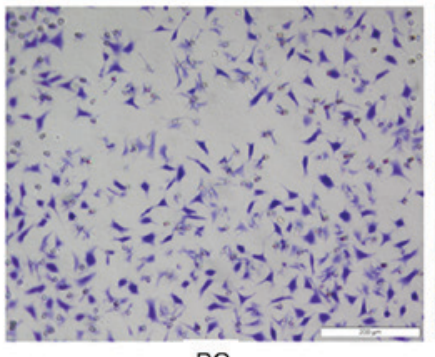

BC

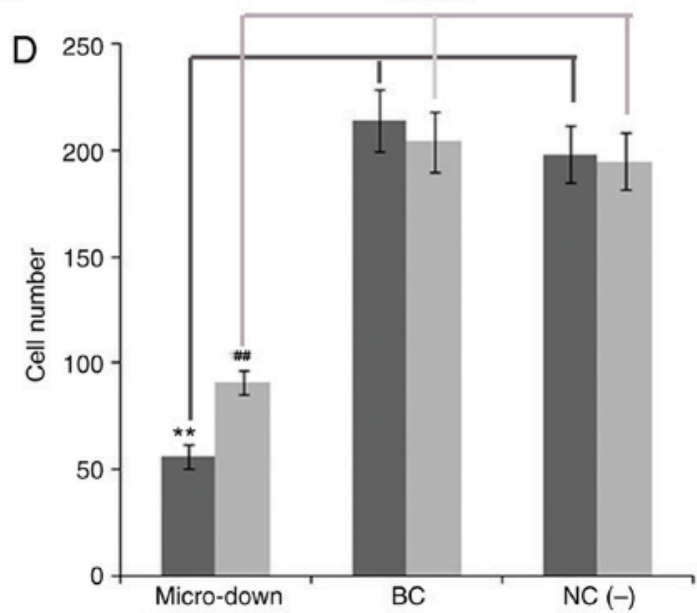

Figure 4. Effects of miR-34b on the migration and invasion of RD-ES cells in vitro. Magnification, x200 (A) Migratory and (B) invasive ability of normal RD-ES cells was inhibited when miR-34b expression was downregulated (top panel). However, miR-34b overexpression improved the migratory and invasive ability of siRNA-transfected-RD-ES cells (bottom panel). Quantification of (C) EWS-FLI1 (-) and (D) EWS-FLI1 (+) cells. The number of cells that passed through the membrane was counted. BC, cell lines that were treated with lentiviral vector alone; $\mathrm{NC}(+)$, normal cell lines that were not transfected with siRNA; siRNA, siRNA-transfected cells; NC(-), normal cell lines that were transfected with specific siRNA; Micro-up, cell lines treated with precursor miR-34b sequences; Micro-down, cell lines treated with complementary sequences of miR-34b; EWS-FLI1 (+), cells that were not transfected with EWS-FLI1 fusion gene siRNA; EWS-FLI1 (-), cells that were transfected with EWS-FLI1 fusion gene siRNA against EWS-FLI1 gene. ${ }^{* *} \mathrm{P}<0.01$, ${ }^{\# \#} \mathrm{P}<0.01$. EWS, Ewing's sarcoma breakpoint region 1; FLI1, friend leukemia integration 1 transcription factor; miR, microRNA; siRNA, small interfering RNA. 

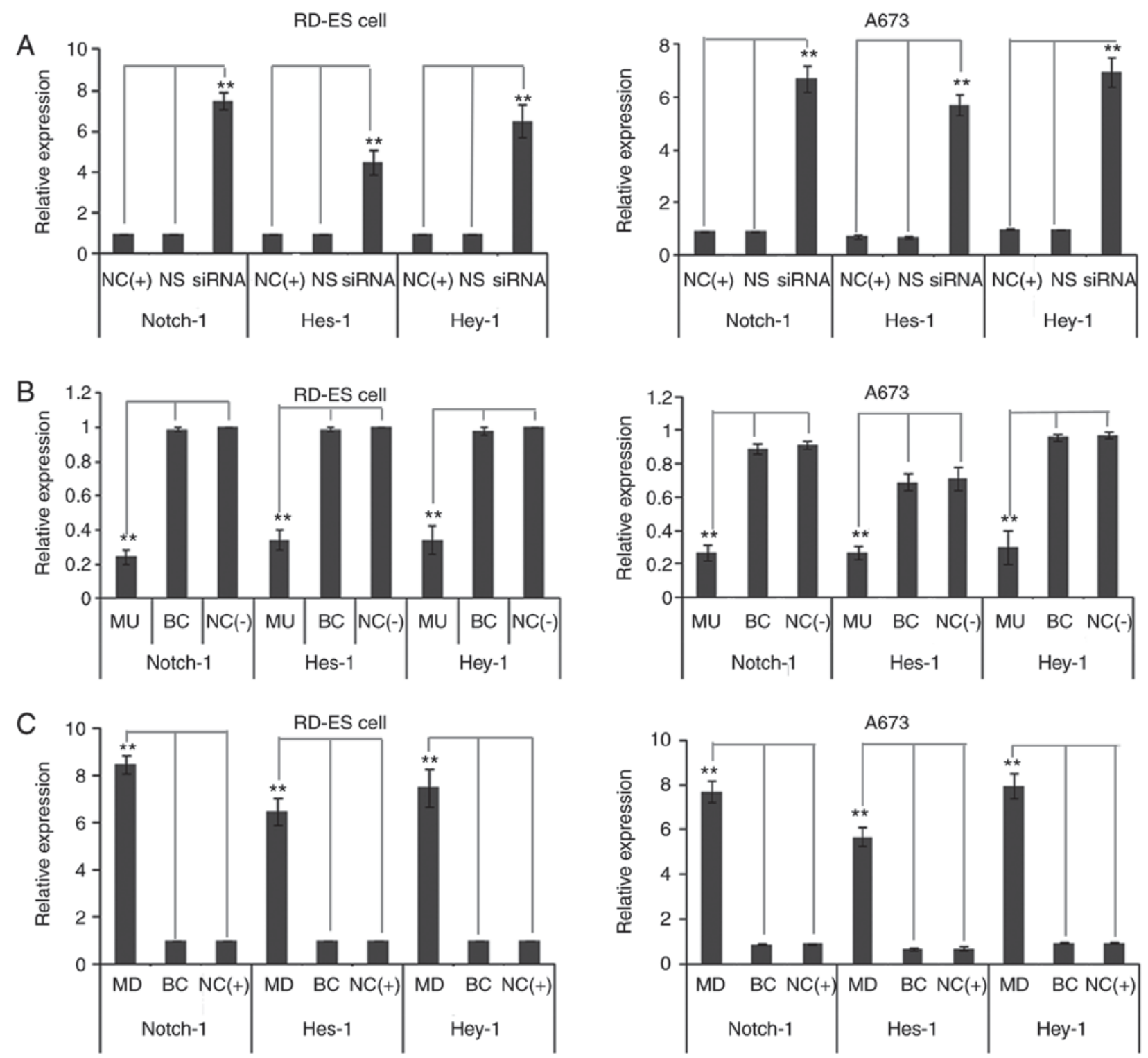

Figure 5. mRNA expression levels of Notch1, Hes-1 and Hey-1 demonstrated the negative association with that of EWS-FLI1 and miR-34b in RD-ES and A673 cells. (A) mRNA expression levels of Notch-1, Hes-1 and Hey-1 were increased when the expression of the EWS-FLI1 fusion gene was downregulated by siRNA in RD-ES and A673 cells. (B) Conversely, mRNA expression levels were inhibited after the siRNA-transfected cells were treated with miR-34b precursor sequences. (C) Notch-1, Hes-1 and Hey-1 mRNA expression was increased after miR-34b was downregulated in normal cells. BC, cell lines that were treated with lentiviral vector alone; $\mathrm{NC}(+)$, normal cell lines that were not transfected with siRNA; NS, cells transfected with non-targeting siRNA; siRNA, siRNA-transfected cells; NC(-), normal cell lines that were transfected with specific siRNA; MU, cell lines treated with precursor miR-34b sequences; MD, cell lines treated with complementary sequences of miR-34b. ${ }^{* * *} \mathrm{P}<0.01$. EWS, Ewing's sarcoma breakpoint region 1; FLI1, friend leukemia integration 1 transcription factor; Hes1, Hes family BHLH transcription factor 1; Hey1, Hes-related family BHLH transcription factor with YRPW motif 1; miR, microRNA; siRNA, small interfering RNA.

respectively. These reporter constructs were co-transfected with miR-34b inhibitor or miR-NC into RD-ES and A673 cells, and luciferase activity was measured. It was revealed that miR-34b inhibition led to significantly increased luciferase activity of pmiR-RB-REPORT-NOTCH1-3'UTR ( $<<0.05$; Fig. 7), but had no effect on pmiR-RB-REPORT-NOTCH1-3'U TR-mut. Taken together, these results suggested that miR-34b may directly target the 3'-UTR of Notch1.

\section{Discussion}

Accumulating evidence has suggested that miRNA shave a key role in tumorigenesis through the regulation of their target genes. Previous studies involving in vitro experiments and analysis of clinical samples have demonstrated a direct link between miRNA function and the EWS-FLI1 fusion gene (11-13,23). In particular one member of the miR-34 family, miR-34a, has been reported to predict the survival of patients with Ewing's sarcoma (23). Therefore, the present study aimed to investigate miR-34b expression in Ewing's sarcoma, a disease predominantly characterized by the EWS-FLI1 fusion gene (1). Firstly, gene expression of the EWS-FLI1 gene in the NT samples was detected by RT-PCR followed by gel electrophoresis and the results indicated that the EWS-FLI1 fusion gene was not expressed in all NT samples. Subsequently, RT-PCR was performed to detect the expression levels of 
A
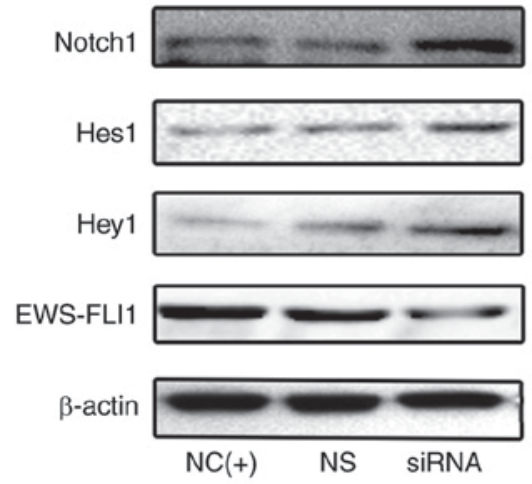

$\mathrm{D}$

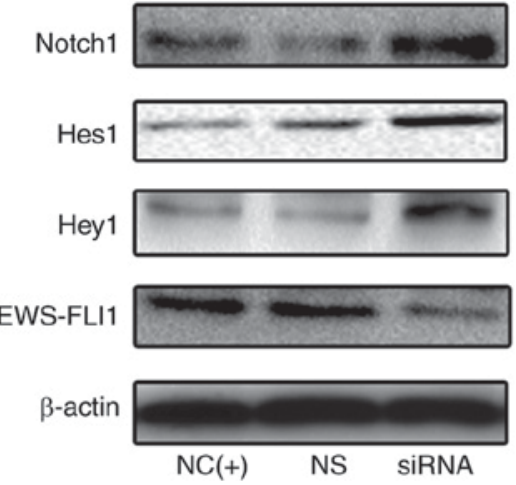

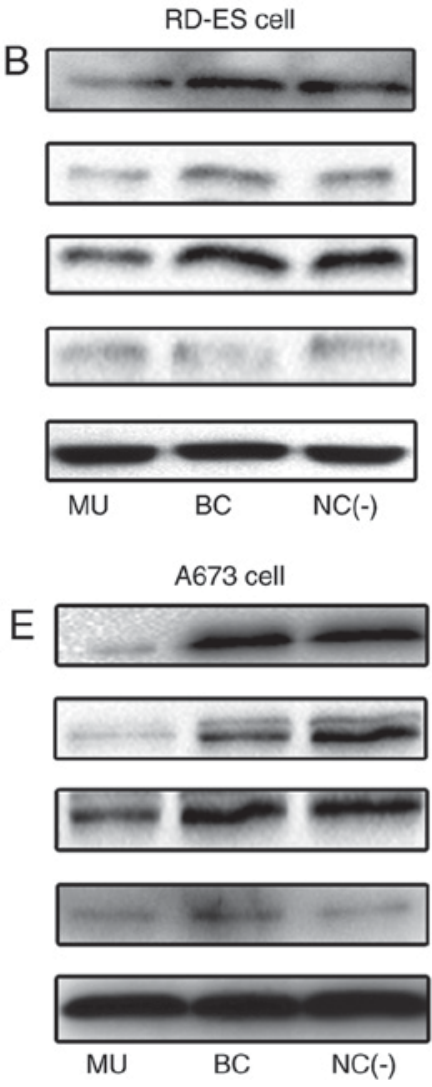
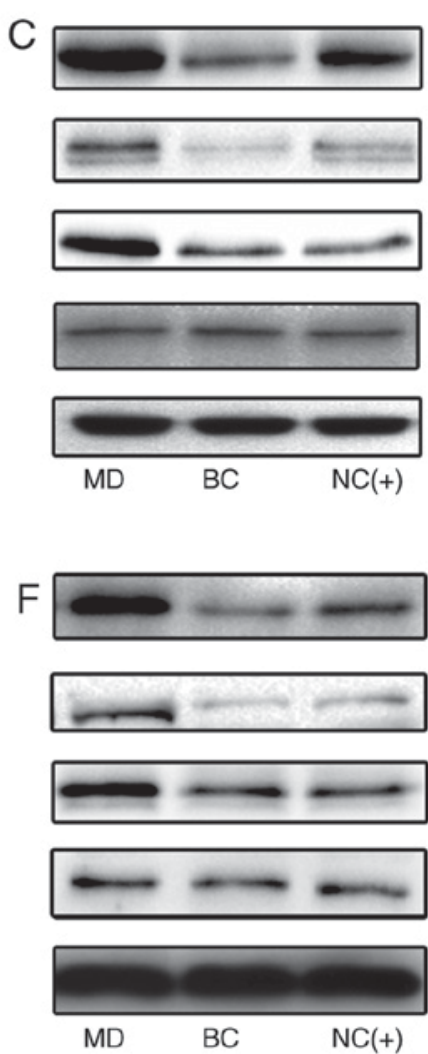

Figure 6. Protein expression levels of Notch1, Hes-1 and Hey-1 demonstrated the negative association with EWS-FLI1 and miR-34b in RD-ES and A673 cells. (A) The protein expression levels of Notch-1, Hes-1 and Hey-1 were increased following EWS-FLI1 repression in RD-ES cells. (B) The expression of Notch-1, Hes-1 and Hey-1 were decreased after miR-34b was upregulated in RD-ES cells in which EWS-FLI1 is repressed. (C) The expression of Notch-1, Hes-1 and Hey-1 were increased after miR-34b was downregulated in RD-ES cells. (D) The protein expression levels of Notch-1, Hes-1 and Hey-1 were increased following EWS-FLI1 repression in A673 cells. (E) The expression of Notch-1, Hes-1 and Hey-1 were decreased following miR-34b was upregulated in A673 cells in which EWS-FLI1 is repressed. (F) The expression of Notch-1, Hes-1 and Hey-1 were increased after miR-34b was downregulated in A673 cells. BC, cell lines that were treated with lentiviral vector alone; $\mathrm{NC}(+)$, normal cell lines that were not transfected with siRNA; NS, cells transfected with non-targeting siRNA; siRNA, siRNA-transfected cells; NC(-), normal cell lines that were transfected with specific siRNA; MU, cell lines treated with precursor miR-34b sequences; MD, cell lines treated with complementary sequences of miR-34b. EWS, Ewing's sarcoma breakpoint region 1; FLI1, friend leukemia integration 1 transcription factor; Hes1, Hes family BHLH transcription factor 1; Hey1, Hes-related family BHLH transcription factor with YRPW motif 1; miR, microRNA; siRNA, small interfering RNA.

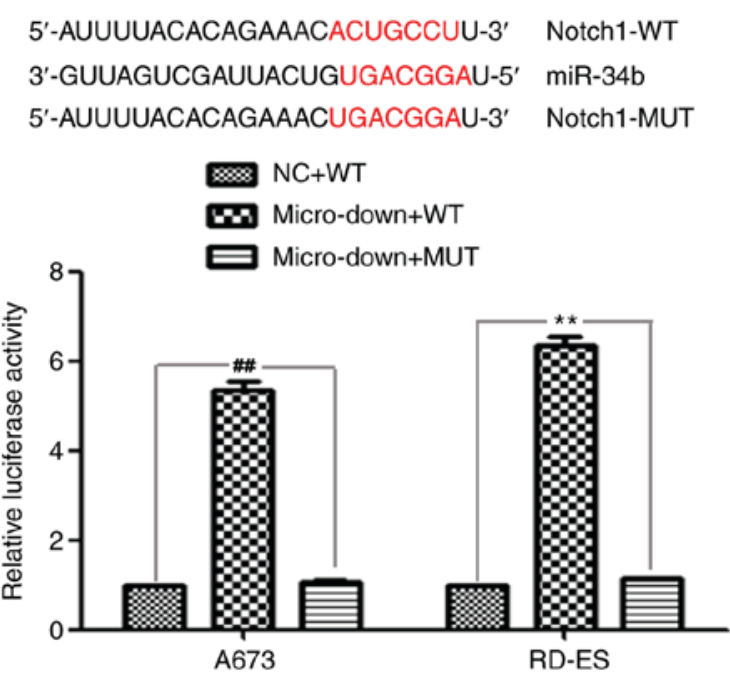

Figure 7. Dual-luciferase reporter assay. Relative luciferase activity was normalized to Renilla luciferase activity following co-transfection of RD-ES and A673 cells with the miR-34b inhibitor and pmiR-RB-REPORT construct containing WT or MUT NOTCH1 3'-UTR. Experiments were performed in triplicate. ${ }^{\# \#} \mathrm{P}<0.01$ and, ${ }^{* *} \mathrm{P}<0.01$ vs. NC+WT or Micro-down+MUT as illustrated by the lines. 3'-UTR, 3'-untranslated region; miR, microRNA; MUT, mutated; NC, negative control; WT, wild type.
miR-34b using stem-loop primers. Notably, the expression levels of miR-34b were higher in tumor samples compared within NT samples. In addition, the expression levels of miR-34b were higher in EWS-FLI1-positive samples compared with in EWS-FLI1-negative samples. It has been demonstrated at the molecular level that $10 \%$ of Ewing's sarcoma cases harbor the EWS-ERG fusion transcript $(28,30)$. FLI1 and ERG belong to the ETS transcription factor family, which all share a highly conserved DNA-binding domain, and can act as aberrant transcription factors when their genes fuse with the EWS gene (1,31-34). The difference inmiR-34b expression inEWS-FLI1-and EWS-ERG-positive samples may be associated with the differential regulatory abilities of the FLI1 and ERG genes (35). miR-34b expression was also detected in Ewing's sarcoma cell lines and miR-34b expression was inhibited when the cells were transfected with EWS-FLI1-specific siRNA. These results indicated that miR-34b may be upregulated in Ewing's sarcoma biopsy samples, particularly those harboring the EWS-FLI1 fusion gene, and Ewing's sarcoma cell lines. The results were consistent with other studies demonstrating the involvement of miRNAs in Ewing's sarcoma as well as other solid tumors $(11,36)$. 
Studies have demonstrated that miRNAs can act as oncogenes or tumor suppressor genes, and that widespread alterations in miRNA expression patterns are highly associated with various human cancers $(37,38)$. miR-34b is a member of the evolutionarily conserved miR-34family, and can exert tumor suppressive effects by downregulating its target genes, including Notch, B-cell lymphoma 2andhigh mobility group AT-hook 2 (22). miR-34b also has an important role in p53-induced cell cycle arrest, cell senescence, apoptosis and other biological functions (39). Numerous studies have demonstrated that miR-34b inhibits cell proliferation, migration and invasion $(20,21,40)$; however, miR-34b also has an oncogenic role in esophageal squamous cell carcinoma (41). To the best of our knowledge, the functions of miR-34b in Ewing's sarcoma have not yet been elucidated.

Uncontrolled cell proliferation leads to tumor growth, and aggressive tumor cell metastasis promotes spreading of tumor cells to distal sites. Therefore, the present study investigated the role of miR-34b in proliferation, adhesion, migration and invasion of tumor cells. Firstly, the precursor sequence of miR-34b was infected into siRNA-transfected Ewing's sarcoma cells. The proliferative, migratory and invasive abilities of the cells were significantly enhanced following upregulation of miR-34b expression. The adhesive ability was also enhanced in RD-ES cells, but not in A673 cells. According to the ATCC, these cell lines possess different culture characteristics that could account for the differences observed. RD-ES cells grow as a loosely attached monolayer in small clusters, whereas A673 cells are fully adherent (42). Subsequently, the complementary sequence was used to downregulate miR-34b expression and, as expected, the adhesive abilities were inhibited. These results indicated that miR-34b may serve an oncogenic role in Ewing's sarcoma.

Notch is an evolutionarily conserved signaling pathway that affects cell fate, proliferation, migration and invasion (43). Notch can be oncogenic or tumor suppressive in human cancer (44-47); therefore, the role of Notch needs to be further clarified in the context of different types of cancer. Previous studies have demonstrated that suppression of EWS-FLI1 reactivates Notch signaling in ESFT cells, resulting in cell cycle arrest (48), and using microarray analysis, Notch signaling has been revealed to be crucial for the metastatic phenotype (49). SinceNotch1 is expressed in ESFT cell lines $(48,50)$ and is a target gene of miR-34b $(25,51,52)$, the present study investigated the expression levels of Notch1in A673 and RD-ES cell lines. The results indicated that suppression of EWS-FLI1 couldincreaseNotchlexpression at both the mRNA and protein levels. Conversely, when miR-34b expression was upregulated, the mRNA and protein levels of Notch1 were decreased. It has previously been reported that Heyl is the main downstream effector of Notch signaling and that Hes1 is uncoupled from the Notch pathway in ESFT cells (53). In the present study, the observation was made that the mRNA and protein expression levels of Hes1 and Heyl were downregulated by miR-34b, indicating that the EWS-FLI1 fusion gene may suppress the Notch1 signaling pathway, at least in part via miR-34b.

miRNAs can function as either tumor suppressor genes or oncogenes depending on their target genes $(54,55)$. Tumor suppressive miRNAs that target tumor-promoting genes are repressed in cancer, whereas oncogenic miRNAs that target tumor suppressor genes are upregulated in cancer. For tumors where Notch1 serves an oncogenic role $(44,56)$, miR-34 has been demonstrated to be tumor suppressive $(25,51,57)$. Therefore, as Notch1 acts as a tumor suppressor in Ewing's sarcoma, miR-34b may be exerting its oncogenic effects through this gene. Using a dual-luciferase reporter assay, it was revealed that miR-34b may directly modulate the expression of Notch1 by binding to the 3'-UTR region (sequence 181-187) of Notch1.

Despite overexpression of miR-34b in Ewing's sarcoma samples and cell lines, the underlying mechanisms by which EWS-FLI1 affects miR-34b remain unclear. miR-34 has been reported to be directly induced by the c-MYC proto-oncogene, which is a known EWS-FLI1 target gene (58), thus suggesting that EWS-FLI1 may indirectly modulate miR-34b via c-Myc induction. In conclusion, EWS-FLI1 may modulate miR-34b expression through direct or indirect mechanisms, and miR-34b appears to serve an oncogenic role in Ewing's sarcoma by downregulating Notch1.

\section{Acknowledgements}

The authors would like to thank the Department of Science \& Technology of Shandong province for their continued support.

\section{Funding}

The present study was supported by the Nature Science Foundation of Shandong Province for Young Scholars (China; grant no. 2015ZRE27529).

\section{Availability of data and materials}

The datasets used or analyzed during the current study are available from the corresponding author on reasonable request.

\section{Authors' contributions}

QL and SZ conceived and designed the study. QL and SZ performed the experiments. DL and ML provided some of the samples and experiment methods. QL wrote the paper. SZ reviewed and edited the manuscript. All authors read and approved the manuscript.

\section{Ethics approval and consent to participate}

The present study was approved by the Institutional Review Boards of Qilu Hospital of Shandong University (Jinan, China) and Shandong Provincial Hospital Affiliated to Shandong University (Jinan, China). Written informed consent was obtained from all patients.

\section{Consent for publication}

The study was done following agreement from the local ethics committee and with the patients' informed consent.

\section{Competing interests}

The authors declare that they have no competing interests. 


\section{References}

1. Riggi $\mathrm{N}$ and Stamenkovic I: The Biology of Ewing sarcoma Cancer Lett 254: 1-10, 2007.

2. Bacci G, Forni C, Longhi A, Ferrari S, Donati D, De Paolis M, Barbieri E, Pignotti E, Rosito P and Versari M: Long-term outcome for patients with non-metastatic Ewing's sarcoma treated with adjuvant and neoadjuvant chemotherapies. 402 patients treated at Rizzoli between 1972 and 1992. Eur J Cancer 40: $73-83,2004$

3. Grier HE, Krailo MD, Tarbell NJ,Link MP, FryerCJ,Pritchard DJ, Gebhardt MC, Dickman PS, Perlman EJ, Meyers PA, et al: Addition of ifosfamide and etoposide to standard chemotherapy for Ewing's sarcoma and primitive neuroectodermal tumor of bone. N Engl J Med 348: 694-701, 2003.

4. Esiashvili N, Goodman M and Marcus RB Jr: Changes in incidence and survival of Ewing sarcoma patients over the past 3 decades: Surveillance epidemiology and end results data. J Pediatr Hematol Oncol 30: 425-430, 2008.

5. Riggi N, Suva ML, Suva D, Cironi L, Provero P, Tercier S, Joseph JM, Stehle JC, Baumer K, Kindler V and Stamenkovic I: EWS-FLI-1 expression triggers a Ewing's sarcoma initiation program in primary human mesenchymal stem cells. Cancer Res 68: 2176-2185, 2008

6. Riggi N, Cironi L, Provero P, Suva ML, Kaloulis K, Garcia-Echeverria C, Hoffmann F, Trumpp A and Stamenkovic I: Development of Ewing's sarcoma from primary bone marrow-derived mesenchymal progenitor cells. Cancer Res 65 : 11459-1168, 2005

7. Jedlicka P: Ewing Sarcoma, an enigmatic malignancy of likely progenitor cell origin, driven by transcription factor oncogenic fusions. Int J Clin Exp Pathol 3: 338-347, 2010

8. Aryee DN, Niedan S, Kauer M, Schwentner R, Bennani-Baiti IM, Ban J, Muehlbacher K, Kreppel M, Walker RL, Meltzer P, et al: Hypoxia modulates EWS-FLI1 transcriptional signature and enhances the malignant properties of Ewing's sarcoma cells in vitro. Cancer Res 70: 4015-4023, 2010.

9. Bachmaier R, Aryee DN, Jug G, Kauer M, Kreppel M, Lee KA and Kovar H: O-GlcNAcylation is involved in the transcriptional activity of EWS-FLI1 in Ewing's sarcoma. Oncogene 28: 1280-1284, 2009.

10. Hancock JD and Lessnick SL: A transcriptional profiling meta-analysis reveals a core EWS-FLI gene expression signature. Cell Cycle 7: 250-256, 2008

11. De Vito C, Riggi N, Suva ML, Janiszewska M, Horlbeck J, Baumer K, Provero P and Stamenkovic I: Let-7a is a direct EWS-FLI-1 target implicated in Ewing's sarcoma development. PLoS One 6: e23592, 2011.

12. Ban J, Jug G, Mestdagh P, Schwentner R, Kauer M, Aryee DN, Schaefer KL, Nakatani F, Scotlandi K, Reiter M, et al Hsa-mir-145 is the top EWS-FLI1-repressed microRNA involved in a positive feedback loop in Ewing's sarcoma. Oncogene 30: 2173-2180, 2011

13. Riggi N, Suva ML, De Vito C, Provero P, Stehle JC, Baumer K, Cironi L, Janiszewska M, Petricevic T, Suvà D, et al: EWS-FLI-1 modulates miRNA145 and SOX2 expression to initiate mesenchymal stem cell reprogramming toward Ewing sarcoma cancer stem cells. Genes Dev 24: 916-932, 2010.

14. Ambros V: The functions of animal microRNAs. Nature 431: 350-355, 2004

15. Bartel DP: MicroRNAs: Genomics, biogenesis, mechanism, and function. Cell 116: 281-297, 2004.

16. Papagiannakopoulos T and Kosik KS: MicroRNAs: Regulators of oncogenesis and stemness. BMC Med 6: 15, 2008.

17. Sandberg R, Neilson JR, Sarma A, Sharp PA and Burge CB Proliferating cells express mRNAs with shortened 3' untranslated regions and fewer microRNA target sites. Science 320: $1643-1647,2008$

18. McKinsey EL, Parrish JK, Irwin AE, Niemeyer BF, Kern HB, Birks DK, Jedlicka P: A novel oncogenic mechanism in Ewing sarcoma involving IGF pathway targeting by EWS/Fli1-regulated microRNAs. Oncogene 30: 4910-4920, 2011.

19. Robin TP, Smith A, McKinsey E, Reaves L, Jedlicka P and Ford HL: EWS/FLI1 regulates EYA3 in Ewing sarcoma via modulation of miRNA-708, resulting in increased cell survival and chemoresistance. Mol Cancer Res 10: 1098-1108, 2012.

20. Dong F and Lou D: MicroRNA-34b/c suppresses uveal melanoma cell proliferation and migration through multiple targets. Mol Vis 18: 537-546, 2012.
21. Majid S, Dar AA, Saini S, Shahryari V, Arora S, Zaman MS, Chang I, Yamamura S, Tanaka Y, Chiyomaru T, et al: miRNA-34b inhibits prostate cancer through demethylation, active chromatin modifications, and AKT pathways. Clin Cancer Res 19: 73-84, 2013.

22. Hermeking H: The miR-34 family in cancer and apoptosis. Cell Death Differ 17: 193-199, 2010

23. Nakatani F, Ferracin M, Manara MC, Ventura S, Del Monaco V, Ferrari S, Alberghini M, Grilli A, Knuutila S, Schaefer KL, et al: miR-34a predicts survival of Ewing's sarcoma patients and directly influences cell chemo-sensitivity and malignancy. J Pathol 226: 796-805, 2012.

24. Zweidler-McKay PA: Notch signaling in pediatric malignancies. Current Oncol Rep 10: 459-468, 2008

25. Ji Q, Hao X, Zhang M, Tang W, Yang M, Li L, Xiang D, Desano JT, Bommer GT, Fan D, et al: MicroRNA miR-34 inhibits human pancreatic cancer tumor-initiating cells. PLoS One 4: e6816, 2009.

26. Weiler J, Hunziker J and Hall J: Anti-miRNA oligonucleotides (AMOs): Ammunition to target miRNAs implicated in human disease? Gene Ther 13: 496-502, 2006.

27. Livak KJ and Schmittgen TD: Analysis of relative gene expression data using real-time quantitative PCR and the 2(-Delta Delta C(T)) method. Methods 25: 402-408, 2001

28. Delattre O, Zucman J, Melot T, Garau XS, Zucker JM, Lenoir GM, Ambros PF, Sheer D, Turc-Carel C, Triche TJ, et al: The Ewing family of tumors-a subgroup of small-round-cell tumors defined by specific chimeric transcripts. N Engl J Med 331: 294-299, 1994.

29. Tsugita M, Yamada N, Noguchi S, Yamada K, Moritake H, Shimizu K, Akao Y and Ohno T: Ewing sarcoma cells secrete EWS/Fli-1 fusion mRNA via microvesicles. PLoS One 8: e77416, 2013.

30. Zucman J, Melot T, Desmaze C, Ghysdael J, Plougastel B, Peter M, Zucker JM, Triche TJ, Sheer D, Turc-Carel C, et al: Combinatorial generation of variable fusion proteins in the Ewing family of tumours. EMBO J 12: 4481-4487, 1993.

31. Turc-Carel C, Aurias A, Mugneret F, Lizard S, Sidaner I, Volk C, Thiery JP, Olschwang S, Philip I, Berger MP, et al: Chromosomes in Ewing's sarcoma. I. An evaluation of 85 cases of remarkable consistency of $\mathrm{t}(11 ; 22)(\mathrm{q} 24 ; \mathrm{q} 12)$. Cancer Genet Cytogenet 32: 229-238, 1988.

32. Delattre O,Zucman J, Plougastel B, Desmaze C, Melot T, Peter M, Kovar H, Joubert I, de Jong P, Rouleau G, et al: Gene fusion with an ETS DNA-binding domain caused by chromosome translocation in human tumours. Nature 359: 162-165, 1992.

33. Douglass EC, Valentine M, Green AA, Hayes FA and Thompson EI: $t(11 ; 22)$ and other chromosomal rearrangements in Ewing's sarcoma. J Natl Cancer Inst 77: 1211-1215, 1986

34. May WA, Gishizky ML, Lessnick SL, Lunsford LB, Lewis BC, Delattre O, Zucman J, Thomas G and Denny CT: Ewing sarcoma 11;22 translocation produces a chimeric transcription factor that requires the DNA-binding domain encoded by FLI1 for transformation. Proc Natl Acad Sci USA 90: 5752-5756, 1993.

35. Im YH, Kim HT, Lee C, Poulin D, Welford S, Sorensen PH, et al: EWS-FLI1, EWS-ERG, and EWS-ETV1 oncoproteins of Ewing tumor family all suppress transcription of transforming growth factor beta type II receptor gene. Cancer Res 60: 1536-1540, 2000.

36. Mendell JT: miRiad roles for the miR-17-92 cluster in development and disease. Cell 133: 217-22, 2008.

37. Esquela-Kerscher A and Slack FJ: Oncomirs-microRNAs with a role in cancer. Nat Rev Cancer 6: 259-269, 2006.

38. Bartel DP: MicroRNAs: Target recognition and regulatory functions. Cell 136: 215-233, 2009

39. Hermeking H: p53 enters the microRNA world. Cancer Cell 12: 414-418, 2007.

40. Yamazaki H, Chijiwa T, Inoue Y, Abe Y, Suemizu H, Kawai K, Wakui M, Furukawa D, Mukai M, Kuwao S, et al: Overexpression of the miR-34 family suppresses invasive growth of malignant melanoma with the wild-type p53 gene. Exp Ther Med 3: 793-796, 2012

41. Harata K, Ishiguro H, Kuwabara Y, Kimura M, Mitsui A, Ogawa R, Katada T, Tanaka T, Shiozaki M and Fujii Y: MicroRNA-34b has an oncogenic role in esophageal squamous cell carcinoma. Oncol Lett 1: 685-689, 2010.

42. Giard DJ, Aaronson SA, Todaro GJ, Arnstein P, Kersey JH, Dosik H and Parks WP: In vitro cultivation of human tumors: Establishment of cell lines derived from a series of solid tumors. J Natl Cancer Inst 51: 1417-1423, 1973. 
43. Artavanis-Tsakonas S, Rand MD and Lake RJ: Notch signaling: Cell fate control and signal integration in development. Science 284: 770-776, 1999.

44. Lobry C, Oh P and Aifantis I: Oncogenic and tumor suppressor functions of Notch in cancer: It's NOTCH what you think. J Exp Med 208: 1931-1935, 2011

45. Avila JL and Kissil JL: Notch signaling in pancreatic cancer: Oncogene or tumor suppressor? Trends Mol Med 19: 320-327, 2013.

46. Yap LF, Lee D, Khairuddin A, Pairan MF, Puspita B, Siar CH and Paterson IC: The opposing roles of NOTCH signalling in head and neck cancer: A mini review. Oral Dis 21: 850-857, 2015.

47. Rampias T, Vgenopoulou P, Avgeris M, Polyzos A, Stravodimos K, Valavanis C, Scorilas A and Klinakis A: A new tumor suppressor role for the Notch pathway in bladder cancer. Nat Med 20: 1199-1205, 2014.

48. Ban J, Bennani-Baiti IM, Kauer M, Schaefer KL, Poremba C, Jug G, Schwentner R, Smrzka O, Muehlbacher K, Aryee DN and Kovar H: EWS-FLI1 suppresses NOTCH-activated p53 in Ewing's sarcoma. Cancer Res 68: 7100-7109, 2008.

49. Schaefer KL, Eisenacher M, Braun Y, Brachwitz K, Wai DH, Dirksen U, Lanvers-Kaminsky C, Juergens H, Herrero D, Stegmaier S, et al: Microarray analysis of Ewing's sarcoma family of tumours reveals characteristic gene expression signatures associated with metastasis and resistance to chemotherapy. Eur J Cancer 44: 699-709, 2008.

50. Baliko F, Bright T, Poon R, Cohen B, Egan SE and Alman BA: Inhibition of notch signaling induces neural differentiation in Ewing sarcoma. Am J Pathol 170: 1686-1694, 2007.
51. Ji Q, Hao X, Meng Y, Zhang M, Desano J, Fan D and Xu L: Restoration of tumor suppressor miR-34 inhibits human p53-mutant gastric cancer tumorspheres. BMC Cancer 8: 266, 2008.

52. Tang Y, Tang Y and Cheng YS: miR-34a inhibits pancreatic cancer progression through Snail1-mediated epithelial-mesenchymal transition and the Notch signaling pathway. Sci Rep 7: 38232, 2017.

53. Bennani-Baiti IM, Aryee DN, Ban J, Machado I, Kauer M, Muhlbacher K, Amann G, Llombart-Bosch A and Kovar H: Notch signalling is off and is uncoupled from HES1 expression in Ewing's sarcoma. J Pathol 225: 353-363, 2011.

54. Sharma S, Kelly TK and Jones PA: Epigenetics in cancer. Carcinogenesis 31: 27-36, 2010.

55. Lee YS and Dutta A: MicroRNAs in cancer. Annu Rev Pathol 4 199-227, 2009.

56. Groth $\mathrm{C}$ and Fortini ME: Therapeutic approaches to modulating Notch signaling: Current challenges and future prospects. Semin Cell Dev Biol 23: 465-472, 2012.

57. Vrba L, Munoz-Rodriguez JL, Stampfer MR and Futscher BW: miRNA gene promoters are frequent targets of aberrant DNA methylation in human breast cancer. PLoS One 8: e54398, 2013.

58. O'Donnell KA, Wentzel EA, Zeller KI, Dang CV and Mendell JT: c-Myc-regulated microRNAs modulate E2F1 expression. Nature 435: 839-843, 2005.

c) (i) () $($ This work is licensed under a Creative Commons Attribution-NonCommercial-NoDerivatives 4.0 International (CC BY-NC-ND 4.0) License. 